\section{Acute Haemorrhagic Colitis Related to Cefuroxime}

The occurrence of acute hacmorrhagic colitis without pseudomembranc formattion in response to treatment with penicillin and its derivatives has been reported, and has reeeived considerable antention $(1-3)$. Despite the wide use of eephalosporins during the last decade, and their similarity in structure ( $\beta$-lactam ring) 10 penicillin. acute hatemorrhagic colitis related to eephalosporins has not been reported. This is the first reported calse of acute hacmorrhagic colitis induced by a cephalosporin (cefuroxime).

A 35 -year-old man wals prescribed ecfuroxime (Zinadol) at a dose of $25(0) \mathrm{mg}$ (wo) times daily. for simusitis. After seven days. this therapy wass stopped. and 24 hours later the pattient developed moderate alsdominal pain and bloody diarrhocal (4-6) movements per day). The physical examination and laboratory results. apart from hemaltocrit $36 \%$, were nomal. Total colonosenpy revealed a diffuse involvement of the sigmoid and descending eolon by mumerous petechiac collected in longitudinal striac (Figure 1). Histological examination of several biopsies of the affected eolon revealed only an acute nonspecific intlammation. When the diagnosis of antibiotic-associated hacmmorhagic eolitis was made. parenteral alimentation started. Remission of bloody diarrhoea wats evident after 48 hours. A control colonoscopy was performed five days latter, and showed that the colonic mucosa wats quite normal. The patient was discharged. and two months later is in good health.

Our patient had no evidence of hypotension, and his young age made a diagnosis of ischatemic colitis unlikely (4). Similar findings have been reported in adult patients with Henochsehönlein purpura and colonic involvement (5). but they are usually associated with arthralgials, stin rash, and renal involvement. The endoscopic tindings, the distribution of the lesions. and the transient nature of the colonic changes seen in out patient. were similar to the findings observed in other reported cases of hatemorrhagic colitis related to penicillin and its derivatives (1 - 3). The mechanism underlying antibiotic-associated hacmorrhagic colitis remains obscure. We believe that the presence of petechiate in the sigmoid and deseending colon in our patient my be related to an allergic vasculitic reaction to cefuroxime restricted to the ecolon.

In conclusion, it should be smphasized that emergency colonoscopy should be carried out when bloody diarrhoea oceurs during ecphalosporin therapy.

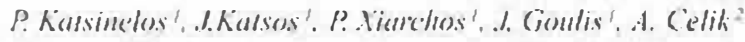

'Dept. of Ciastroenterology. Theagenion Hospital. Thessaloniki. (jrecice

z Centre for Human Nutrition. Unicersity of Sheffield. Sheffichd. United Kingdom

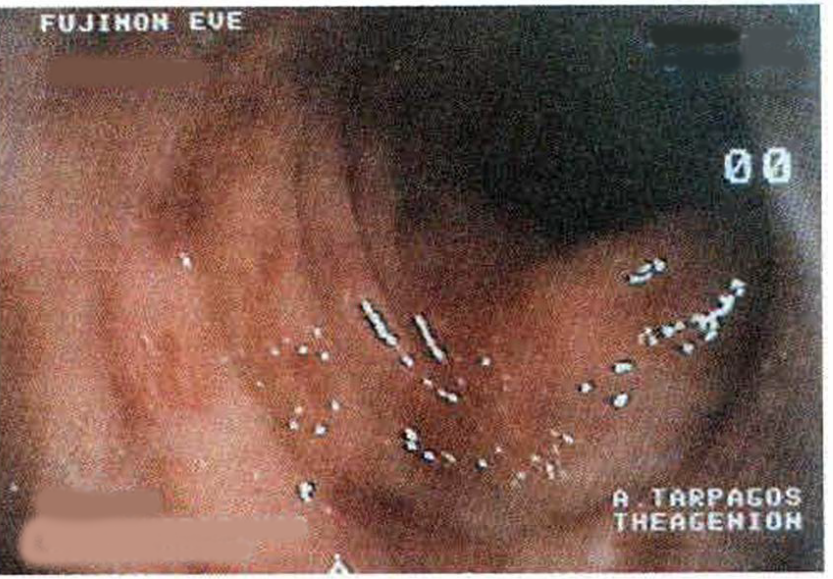

Figure 1: Endoscopic features of the sigmoid colon, showing petechiae collected in longitudinal striae

\section{References}

I. Tottter RB. Pingoud E.(i. Burrell MI. Acute colitis relited to pencillin and penicillin derivatives. Lancet 1978: ii: 70)7-9.

2. Russo, A. Cirino (i. Sanfilippo (i. (irasso (i. Ciiannone (i. Ampicillin-issociated colitis: case report. Endoseopy 1980); 12: $97-9$.

3. lida M. Matsui T. Fuchigami T. Iwashita A, ()mac T. Radicgraphic and endoscopic lindings in penicillin-related nonpsendomembranous colitis. Endoscopy 1985: 17: (24-8.

4. Watamabe M. ()dawara M, Fujitil K. et al. C'linical study of I2 calses of transient ischemic colitis. (iastroenterol Endose 1980): 22: $1581-4$

5. Di Febo (i. Ciisy (i, Biasco (i. Mighlioli M. Colonic involvement in adult patients with Henoch-Séchönlein purpura. Endoscopy 1984: 16: 36-9).

Corresponding futhor

P. Koatsinelos. M. D.

Ydros il

546.38 Thessaloniki

(ireces 